\title{
STRATEGI KOMUNIKASI PEMASARAN PT. TAJUR SURYA ABADI MELALUI PROYEK PERUMAHAN ROYAL TAJUR RESIDENCE DALAM UPAYA MENARIK MINAT BELI KONSUMEN DI KOTA BOGOR
}

\section{STRATEGIC MARKETING COMMUNICATION PT. TAJUR SURYA ABADI TRHOUGH HOUSING ROYAL RESIDENCE WITHIN TO ATTRACT COSTUMER BUYING INTERNET IN BOGOR CITY}

\author{
Z Andreas ${ }^{1}$, I A Ratnamulyani ${ }^{1}$, A A Kusumadinata ${ }^{1 a}$ \\ 1Program Studi Sains Komunikasi, Fakultas Ilmu Sosial Dan Ilmu Politik, Universitas Djuanda Bogor Jl. \\ Tol Ciawi No. 1 Kontak Pos 25 Bogor 16720. \\ a Korespondensi: Ali Alamsyah Kusumadinata, E-mail: alialamsyahkusumadinata@gmail.com
}

(Diterima: 01-05-2019; Ditelaah: 02-05-2019; Disetujui: 28-06-2019)

\begin{abstract}
Bogor city is one of the buffer Jakarta. The air was fresh with high rainfall and topography hilly. This allows people to work in Jakarta and choose to own a house in Bogor. Bogor City also has public and social facilities that can reach all people. The Taj Surya Abadi nuanced resort Royal Tajur was awarded as "The Prospective Housing in Bogor" in Property Indonesia Award 2017. The purpose of this study is to know what marketing communication strategy is already used data analysis technique is analysis SWOT using SWOT matrix and space matrix as the relevant data analysis technique. The results showed Royal Tajur Residence was in Quadrant I (Expansion). Based on SWOT analysis test results using space analysis calculations, describes the situation was very good because there were forces that were utilized to seize the profitable opportunities with aggressive strategy techniques, intending to generate buying interest from consumers.
\end{abstract}

Keywords: Customer buying Interest, strategic marketing communication, swot analysis.

\begin{abstract}
ABSTRAK
Kota Bogor adalah salah satu penyangga Jakarta. Udara segar dengan curah hujan tinggi dan topografi berbukit. Ini memungkinkan orang untuk bekerja di Jakarta dan memilih untuk memiliki rumah di Bogor. Kota Bogor juga memiliki fasilitas umum dan sosial yang dapat menjangkau semua orang. Resor bernuansa Taj Surya Abadi Royal Tajur dianugerahi sebagai "The Prospective Housing di Bogor" dalam Property Indonesia Award 2017. Tujuan dari penelitian ini adalah untuk mengetahui strategi komunikasi pemasaran apa yang sudah digunakan teknik analisis data yaitu analisis SWOT menggunakan matriks SWOT dan ruang matriks sebagai teknik analisis data yang relevan. Hasil penelitian menunjukkan Royal Tajur Residence berada di Kuadran I (Ekspansi). Berdasarkan hasil uji analisis SWOT menggunakan perhitungan analisis ruang, menggambarkan situasi sangat baik karena ada kekuatan yang dimanfaatkan untuk merebut peluang menguntungkan dengan teknik strategi agresif, yang bermaksud untuk menghasilkan minat beli dari konsumen.
\end{abstract}

Kata kunci: Minat beli pelanggan, komunikasi pemasaran strategis, analisis swot. 
Andreas, Z., Ratnamulyani, I. A., Kusumadinata, A. A. (2019). Strategi komunikasi Pemasaran PT. Tajur Surya Abadi Melalui Proyek Perumahan Royal Tajur Residence Dalam Upaya Menarik Minat Beli Konsumen di Kota Bogor. Jurnal Sosial Humaniora, 10(2), 93-107.

\section{PENDAHULUAN}

Kota Bogor termasuk sebagai penyangga ibu kota Jakarta, jarak kedua kota tersebut juga tidak begitu jauh dan dapat dijangkau oleh alat transportasi darat yang telah tersedia. Memiliki iklim udara yang sejuk, dengan curah hujan tinggi dan topografinya berbukit-bukit. Hal ini memungkinkan masyarakat bekerja di Jakarta dan memilih memiliki rumah di Bogor. Kota Bogor juga memiliki fasilitas umum dan sosial yang dapat menjangkau semua kalangan masyarakat (Rasmi, 2009).

Properti terbagi atas dua yaitu properti yang sesungguhnya (real estate) atau properti finansial antara lain saham dan obligasi. Properti perlu dipasarkan dengan strategi yang beragam. Agen real estate bekerja menjual property sebagai pemukiman. Sedangkan property finansial dilakukan dengan perusahaan dalam bentuk investasi, seperti bank dengan memasarkan sekuritas kepada investor institusional atau individual (Kotler \& Keller 2009).

Pertumbuhan penduduk akibat urbanisasi merupakan masalah mendasar yang dihadapi kota-kota sedang berkembang. Termasuk Bogor, yang merupakan penyangga ibu kota Jakarta. Bertambahnya penduduk ini menimbulkan konsekuensi logis yakni kebutuhan hunian terus meningkat setiap tahunnya. Kebutuhan rumah ini banyak peminat dan juga berasal dari kalangan luar dari Kota Bogor (Alexander 2017).

Royal Tajur Residence merupakan perumahan berkonsep resort yang di bangun oleh PT. Tajur Surya Abadi, meraih penghargaan dari Property Indonesia Award (PIA) pada tahun 2017 sebagai "The Prospective Housing in Bogor. PIA sendiri adalah ajang penghargaan properti paling bergengsi di Indonesia yang diselenggarakan setiap tahunnya yang mana dijadikan sebagai barometer bagi perusahaan yang bergelut di bidang properti (Muzakir, 2017). Amalia et al. (2017) menyatakan bahwa strategi komunikasi pemasaran yang dilakukan oleh koran Bogor Today adalah menggunakan personal selling, dengan pendekatan persuasif, menjalin mitra kerjasama dengan berbagai perusahan dan instasi lainnya yang ingin menampilkan iklan di koran Bogor Today. Personal selling yang dilakukan oleh Bogor Today sendiri memiliki hambatan dalam proses pelaksanaannya, seperti kurangnya sumberdaya manusia dan iklim organisasi yang cenderung kurang solid. Selain itu (Indrapraja et al. 2015) menyatakan bahwa strategi komunikasi pemasaran di taman hiburan Jungleland Adventure Theme Park menggunakan strategi periklanan, strategi sales promotion dan strategi public relation. Hal ini berdampak pada jumlah kunjungan yang terus meningkat seiring publikasi promosi.

Strategi adalah upaya mencapai suatu keuntungan yang dilakukan perusahaan melalui berbagai macam kegiatan pemasaran sesuai dengan alokasi sumber daya (Rangkuti 2002). (Kotler \& Keller, 2009) menjelaskan komunikasi pemasaran adalah sarana dimana perusahaan berusaha menginformasikan, membujuk dan mengingatkan konsumen mengenai produk dan merek yang dijual, yang dilakukan secara langsung mau tidak langsung (Hermawan 2012). Penelitian bertujuan untuk mengethui terhadap strategi komunikasi pemasaran yang sudah dilakukan oleh Royal Tajur Residence yang meliputi promosi penjualan, publisitas/ perikalanan dan publik relations dalam menarik minta beli konsumen. 


\section{MATERI DAN METODE}

Penelitian ini menggunakan metode penelitian kuantitatif dengan teknik wawancara mendalam atau Depth interview. Wawancara adalah teknik pengumpulan data dan informasi, dengan proses tatap muka secara langsung bersama informan yang berkompeten terhadap data yang sedang dibutuhkan oleh peneliti secara lengkap (Rakhmat 1998). Penelitian ini menggunakan teknik wawancara sebagai cara utama dalam mengumpulkan data atau informasi. Penelitian dilakukan di Marketing Gallery Royal Tajur Residence. Penelitian dilakukan pada 6 bulan Juni hingga 6 Juli 2018. Data yang digunakan oleh peneliti adalah data primer yang didapatkan secara langsung narasumber asli, data primer dikumpulkan secara khusus oleh peneliti untuk mendapatkan informasi yang sesuai dengan pertanyaan yang diajukan oleh peneliti. Selain itu, peneliti juga menggunakan data sekunder yang diperoleh oleh peneliti secara tidak langsung melalui buku, dokumen-dokumen, dan media online (internet). Teknik pengambilan data pada penelitian ini dengan menggunakan wawancara, observasi, dan dokumentasi. Dalam penelitian ini peneliti menggunakan analisis SWOT sebagai teknik analisis data hasil penelitian, yang terdiri dari matriks SWOT dan matriks Space, sebagai salah satu teknik analisis data yang relevan. Rangkuti (2014) menjelaskan SWOT merupakan singkatan dari Strenghts (kekuatan), Weaknesses (kelemahan), Opportunities (peluang) dan Threats (ancaman) yang menempati lingkunagn internal dan lingkungan eksternal pada sebuah perusahaan, instantasi maupun organisasi lainnya. Analisis SWOT diidentifikasikan sebagai faktor untuk mengetahui secara sistematis komunikasi pemasaran di perusahaan. Analisis ini didasarkan oleh logika yang dapat dimaksimalkan kekuatan dan peluang. Namun secara bersamaaan dapat meminimalisir dari faktor kelemahan dan faktor ancaman dilingkungan perusahaan.

\section{HASIL DAN PEMBAHASAN}

\section{Strategi Komunikasi Pemasaran Royal Tajur Residence dalam Menarik Minat Beli Konsumen}

Strategi komunikasi pemasaran dalam upaya menarik minat beli konsumen, diketahui bahwa manajemen Royal Tajur Residence menyusun sebuah strategi komunikasi pemasaran dengan mengacu pada beberapa elemen komunikasi pemasaran terpadu. Secara garis besarnya bidang pemasaran di perumahan Royal Tajur Residence berada pada bagian marketing officier yang terbagi atas tiga bagian yaitu marketing communication (komunikasi pemasaran), sales promotion (promosi penjualan), dan marketing event (pemasaran melalui acara). Strategi komunikasi pemasaran Royal Tajur Residence meliputi periklanan, promosi penjualan, public relation dan publisitas. Hal yang mendasar dalam pemilihan strategi pemasaran adalah segmentasi dan targeting. Seperti halnya yang telah diungkapkan oleh Supervisor Marketing dari Royal Tajur Residence, bahwa strategi pemasaran berdasarkan target sasarannya yaitu calon pembeli dari kalangan menengah ke atas dengan penghasilan minimal 7 juta.

Pemasaran itu sendiri dikenal istilah 4P (Product, Place, Price dan Promotion). Oleh karena itu, pihak Royal Tajur Residence sadar bahwa produk (Product) yang ditawarkan adalah produk yang berbentuk properti yang merupakan bahan tahan lama (durable goods). Salah satu karakteristik produk barang tahan lama (durable goods) adalah barang yang memiliki nilai pakai yang lama (Kotler, 2004).

\section{Strategi Periklanan}

Strategi periklanan yang dilakukan oleh Royal Tajur Residence adalah menggunakan media BTL (Below the Line) dan media ATL (Above the Line). Strategi periklanan ini dirancang oleh divisi Marketing Communication untuk memberikan informasi (to inform) seputar Royal Tajur 
Residence sebagai usaha menarik minat (to persuade) calon pembeli. Media periklanan yang digunakan oleh Royal Tajur Residence salah satunya bersifat outdoor promotion (media luar ruang). Media periklanan Outdoor Promotion yang digunakan oleh Royal Tajur Residence adalah Billboard, poster dan baliho yang diperbaharui setiap bulannya.

\section{Strategi Promosi Penjualan}

Sales promotion atau biasa disebut promosi penjualan merupakan aktivitas pemasaran yang mengusulkan nilai lebih dari sebuah produk dalam jangka waktu yang ditentukan yang bertujuan mendorong pembelian oleh calon konsumen maupun upaya yang untuk meningkatkan kinerja tenaga penjualan (Hermawan 2012). Promosi penjualan dapat menarik pelanggan baru untuk datang tanpa rencana sebelumnya. Seperti yang dikatakan Supervisor Marketing promosi merupakan salah satu faktor untuk menarik minat calon pembeli, sehingga sangat penting dilakukan. Akan tetapi di usahakan setiap bulannya dilakukan penayangan promosi yang berbeda, sebagai salah satu cara agar tidak monoton sehingga calon pembeli tertarik untuk membeli produk yang ditawarkan. Adapun bentuk-bentuk strategi komunikasi pemasaran yang dilakukan oleh sales promotion Royal Tajur Residence tergambar dalam Tabel 1.

Tabel 1. Strategi Komunikasi Pemasaran

\begin{tabular}{lll}
\hline Jenis & Konten & Kontek \\
Pemasaran & Pemasaran & Pemasaran \\
\hline Langsung & Promo diskon & Iklan \\
& DP (display & pemasaran \\
& payment) di & \\
& acara & \\
& Indonesia & \\
& Property Expo \\
& 2018 di \\
& Jakarta & \\
& Convention & \\
& Center Hall A- \\
\hline Langsung & Promo "beli & Voucher \\
\hline
\end{tabular}

\begin{tabular}{lll}
\hline & $\begin{array}{l}\text { rumah } \\
\text { langsung } \\
\text { belanja" }\end{array}$ & Belanja \\
\hline Langsung & $\begin{array}{l}\text { Promo hadiah } \\
\text { langsung Hadiah } \\
\text { berupa TV }\end{array}$ & Langsung \\
LED setiap & \\
pembelian & \\
rumah Royal & \\
Tajur di & \\
Residence dida & \\
acara & Indonesia \\
Property Expo \\
tahun 2017
\end{tabular}

\section{Strategi Public Relation dan publisitas}

Public relation adalah fungsi yang tidak dapat dipisahkan dari manajemen sebuah organisasi. Tujuannya adalah membentuk niat baik (goodwill), toleransi (tolerance), saling bekerja sama (mutual simbyosis), saling percaya satu sama lain (mutual confidence), saling memahami (mutual understanding), saling menghargai (mutual appreciation), serta untuk mendapatkan opini positif dari masyarakat umum yang bisa dijadikan keuntungan dan menjadi sebuah reputasi yang baik, sesuai denganprinsip dari hubungan yang harmonis, baik hubungan dari dalam maupun dari luar (Hermawan 2012).

Strategi komunikasi pemasaran yang dilakukan oleh Royal Tajur Residence, membina hubungan baik dengan masyarakat dan media. Oleh karena itu, public relation/marketing communication dari Royal Tajur Residence sangar berperan penting dalam proses pemasaran karena mempunyai kegiatan yang cukup banyak untuk membantu menciptakan brand image Royal Tajur Residence. Adapun kegiatankegitan Public Relation dari Royal Tajur Residence adalah :

Press Release Bertujuan memberikan informasi yang dimuat disurat kabar agar dapat menarik perhatian publik terhadap produk, jasa dan organisasi. Dalam hal ini Royal Tajur Residence mengundang media untuk meliput acara yang dilakukan dengan 
memberikan informasi sebelumnya. Setiap event yang diselenggarakan akan diterbitkan melalui media massa seperti koran Sindo, koran Kompas dan majalah Bisnis Indonesia, maupun media online seperti www.bisnis.com, www.wartakota.com,www.propertiinside.co m,www.tribunnews.com. Maupun website resmi Royal Tajur Residence yaitu www.royaltajur.com. Media Relation Royal Tajur Residence selalu menjalin dan menjaga hubungan dengan media. Hal ini merupakan cara efektif untuk membangun, menjaga, dan meningkatkan citra atau reputasi Royal Tajur Residence di mata publik.

Corporate Social Responsibility (CSR) Suryamas Grup telah melaksanakan tanggung jawab sosial dan lingkungan perusahaan (Corporate Social Responsibilities) yang berjalan sesuai dengan rencana strategis yang telah disusun. Semua kegiatan pertanggung jawaban sosial perusahaan (CSR) yang memberikan sebuah kontribusi dengan nilai yang positif bagi perusahaan dan masyarakat yang bertempat tinggal sekitar wilayah opersional perusahaan. Kegiatan CSR dilakukan dalam berbagai bentuk kegiatan acara amal seperti buka bersama dengan masyarakat sekitar dan tokoh masyarakat, menyantuni anak yatim, pemberian sembako dan bantuan sumbangan biaya renovasi masjid masyarakat sekitar.

Event merupakan salah satu cara untuk menyampaikan informasi dan pesan dari sebuah brand, dengan berinteraksi secara langsung dengan customer dan potential event. Event marketing yang diselenggrakan harus berpengaruh dan meninggalkan kesan mendalam bagi seluruh orang yang hadir. Tujuannya adalah supaya customer atau potential customer bisa membekas dipikiran setiap orang dengan kesan yang menyenangkan. Strategi tersebut juga digunakan oleh Royal Tajur Residence dalam menarik minat beli konsumen dan meningkatkan jumlah pembeli. Supervisor Marketing Royal tajur Residence mengungkapkan bahwa event memiliki pengaruh besar, dikarenakan adanya interaksi secara langsung dengan pengunjung atau calon pembeli yang potensial dalam satu waktu. Adapun event yang pernah dilakukan Royal Tajur Residence adalah tergambar dalam Tabel 2.

Tabel 2. Event dalam Pemasaran

\begin{tabular}{|c|c|}
\hline Kegiatan & Deskripsi Kegiatan \\
\hline Wealth and Health & $\begin{array}{l}\text { Royal Tajur Residence bersama rumah sakit Siloam } \\
\text { dan Bank Panin menyelenggarakan Talk Show } \\
\text { kesehatan dengan pembicara dokter Dengan tema } \\
\text { "Pencegahan Penuaan Sendi". Acara tersebut } \\
\text { diselenggarakan di Marketing Gallery Royal Tajur } \\
\text { dan dimeriahkan juga oleh berbagai kegiatan } \\
\text { lainnya seperti fun walk, bazaar, car test drive dan } \\
\text { health check. }\end{array}$ \\
\hline Pameran Indonesia Property Exро 2018 & $\begin{array}{l}\text { Royal Tajur Residence mengikuti pameran di } \\
\text { Indonesia Property Expo yang merupakan } \\
\text { apameran properti terbesar di Indonesia. Acara } \\
\text { tersebut digelar di Hall A-26 Jakarta Convention } \\
\text { Center (JCC). }\end{array}$ \\
\hline Pameran di Botani Square & $\begin{array}{l}\text { Royal Tajur Residence mengadakan pameran di } \\
\text { kota Bogor tepatnya di Botani Square. }\end{array}$ \\
\hline Royal Tajur Foto Contest & $\begin{array}{l}\text { Royal Tajur Residence mengadakan kontes foto, } \\
\text { dengan hadiah voucher bel anja sebesar } 1,8 \text { juta } \\
\text { rupiah. }\end{array}$ \\
\hline
\end{tabular}


Berdasarkan hasil penelitian yang didapatkan, ada beberapa strategi yang dilakukan oleh divisi marketing event Royal Tajur Residence. Adanya event yang sering diadakan oleh Royal Tajur Residence diketahui bahwa strategi komunikasi pemasaran melalui event tersebut, dinilai efektif untuk mendapatkan perhatian konsumen. Event juga dinilai efektif dalam meningkatkan citra produk dan meningktakn penjualan, berinteraksi dengan segmentasi pasar dan menambah jumlah pembeli.

\section{Analisis Matriks SWOT}

\section{Matriks Internal Eksternal}

Sebelum mendapatkan hasil dari Matriks SWOT, peneliti terlebih dahulu menentukan faktor internal dan faktor eksternal yang kemudian melakukan identifikasi terhadap nilai kekuatan, nilai kelemahan, nilai peluang dan nilai ancaman dari kedua faktor tersebut di sistem manajemen Royal Tajur Residence, yang mana kedua faktor tersebut menghasilkan dampak positif dan dampak negatif secara bersamaan bagi perusahaan.
Hasil tersebut selanjutnya bisa dijadikan sebuah pedoman bagi perusahaan ketika hendak membuat sebuah keputusan dalam pemasaran produk. Peneliti menggunakan analisis evaluasi internal (IFE) dan analisis evaluasi faktor eksternal (EFE). Identifikasi dan analisis tersebut didapat beberapa hal yang dapat ditonjolkan kemampuan/kekuatan yang dimiliki perusahaan, membuat solusi dari kelemahan yang dimiliki, memanfaatkan peluang yang ada dan menghindari ancaman dalam penyusunan perencanaan berjalannya perusahaan. Berikut adalah analisi IFE dan EFE yang dibuat oleh kelompok kami.

Analisis IFE (Internal Factor Evaluation) Penulis mengidentifikasikan beberapa kriteria internal yang dianggap sebagai kekuatan dan kelemahan internal perusahaan yaitu sebanyak 13 (tiga belas) kriteria yang memiliki bobot masing-masing yang totalnya bernilai 1 . Serta di berikan nilai peringkat kelemahan dan kekuatan yang mana 1-4. 1 berarti lemah, 2 berarti cukup, 3 berarti baik, 4 berarti sangat baik. Adapun IFE adalah tersaji pada Tabel 3.

Tabel 3. Kriteria Internal Matriks SWOT

\begin{tabular}{|c|c|c|c|c|}
\hline No & Kriteria Internal & Bobot & Nilai & $\begin{array}{c}\text { Nilai } \\
\text { Tertimbang }\end{array}$ \\
\hline \multicolumn{5}{|c|}{ Kekuatan } \\
\hline 1 & \multirow{3}{*}{$\begin{array}{l}\text { Hunian yang menawarkan kenyamanan } \\
\text { untuk kualitas hidup penghuninya. } \\
\text { Lokasi strategis berada disepanjang } \\
\text { gariskomersial Jalan Raya Tajur Kota } \\
\text { Bogor bagian selatan. } \\
\text { Cluster rumah vang ditawarkan beragam }\end{array}$} & 0,090 & 4 & 0,36 \\
\hline 2 & & 0,090 & 4 & 0,36 \\
\hline \multirow{3}{*}{$\begin{array}{l}3 \\
4 \\
5\end{array}$} & & 0,070 & 3 & 0,21 \\
\hline & \multirow{2}{*}{$\begin{array}{l}\text { Arsitektur rumah bergaya Eropa modern } \\
\text { Lingkungannya dikelilingi oleh hutan } \\
\text { Biotrop dengan pemandangan spektakuler } \\
\text { Gunung Salak. }\end{array}$} & 0,060 & 3 & 0,18 \\
\hline & & 0,090 & 4 & 0,36 \\
\hline 6 & \multirow{3}{*}{$\begin{array}{l}\text { Memiliki nilai investasi tinggi baik } \\
\text { finansial maupun kesehatan. } \\
\text { Memiliki fasilitas yang lengkap, baik } \\
\text { fasilitas internal maupun eksternal } \\
\text { Rutin memasang iklan lini atas dan lini } \\
\text { bawah setiap bulannya. }\end{array}$} & 0,080 & 4 & 0,32 \\
\hline 7 & & 0,090 & 3 & 0,27 \\
\hline 8 & & 0,060 & 3 & 0,18 \\
\hline
\end{tabular}




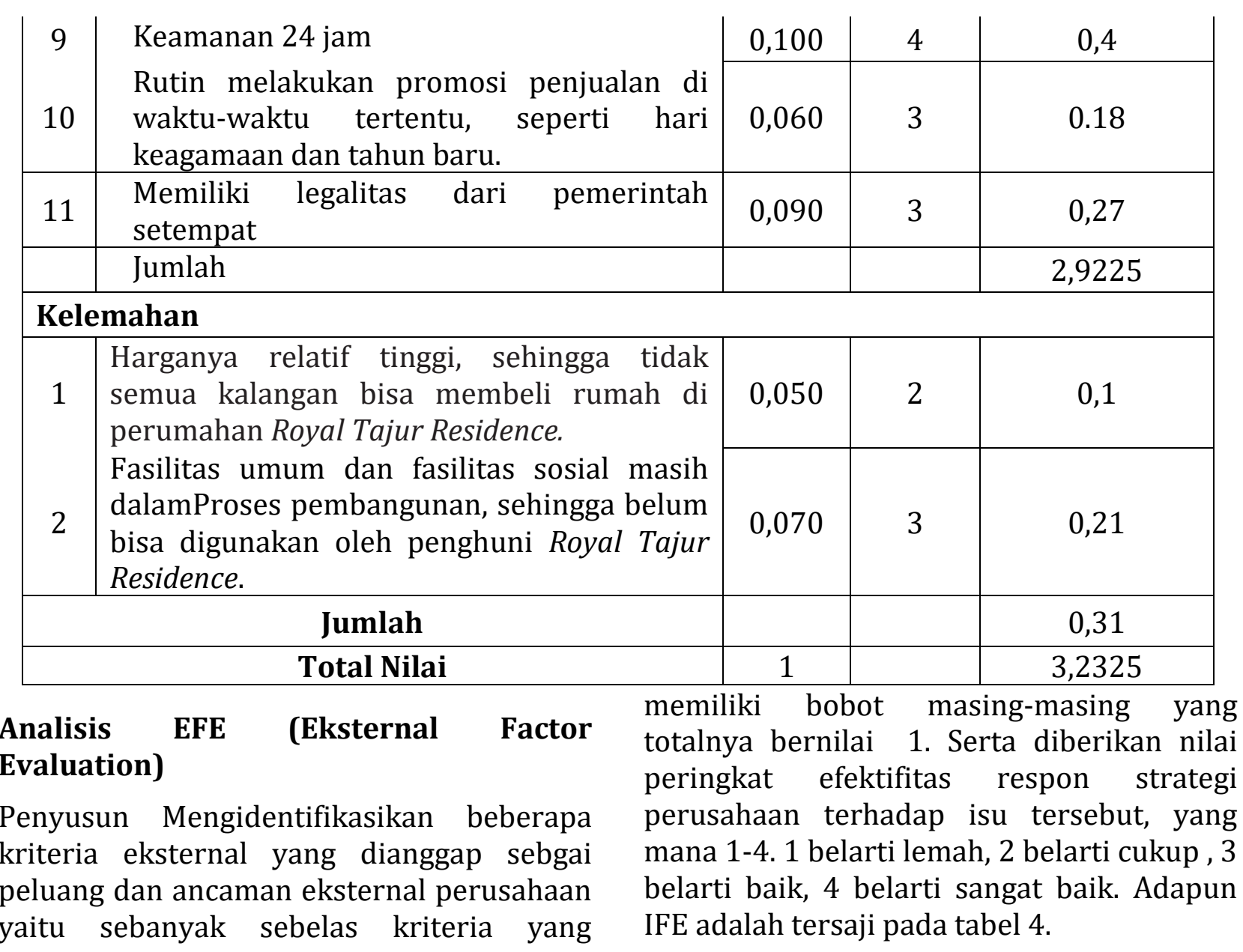

Tabel 4. Kriteria Eksternal matriks SWOT

\begin{tabular}{|c|c|c|c|c|}
\hline No & Kriteria Eksternal & Bobot & Nilai & $\begin{array}{c}\text { Nilai } \\
\text { Tertimbang }\end{array}$ \\
\hline \multicolumn{5}{|c|}{ Peluang } \\
\hline \multirow{2}{*}{$\begin{array}{l}1 \\
2\end{array}$} & \multirow{3}{*}{$\begin{array}{l}\text { Makin mudahnya akses menuju Bogor, } \\
\text { dengan akan dibangunnya jalan raya } \\
\text { Bogor Inner Ring Road (BIRR) dan } \\
\text { pembangunan Tol Bocimi yang akan } \\
\text { segera beroperasi. } \\
\text { Mendapatkan penghargaan nasional } \\
\text { sebagai The Prospective Housing in Bogor } \\
\text { di acara penghargaan properti terbesar } \\
\text { Indonesia Property Award tahun } 2017 \text {. } \\
\text { Berhubungan baik dengan media massa } \\
\text { (media relation), di media cetak dan } \\
\text { media online. }\end{array}$} & 0,100 & 4 & 0,4 \\
\hline & & 0,100 & 3 & 0,3 \\
\hline 3 & & 0,095 & 3 & 0,285 \\
\hline \multirow{3}{*}{$\begin{array}{l}4 \\
5 \\
6 .\end{array}$} & \multirow{3}{*}{$\begin{array}{l}\text { Menjaga hubungan dengan } \\
\text { penghuni/pembeli (retention). } \\
\text { Pengembangan apartemen Royal Height } \\
\text { Kebutuhan masyarakat urban mengenai } \\
\text { hunian yang alami }\end{array}$} & 0,085 & 3 & 0,255 \\
\hline & & 0,095 & 3 & 0,285 \\
\hline & & 0,095 & 4 & 0,38 \\
\hline
\end{tabular}




\begin{tabular}{|c|c|c|c|c|}
\hline No & Kriteria Eksternal & Bobot & Nilai & $\begin{array}{c}\text { Nilai } \\
\text { Tertimbang }\end{array}$ \\
\hline & Jumlah & & & 1,905 \\
\hline \multicolumn{5}{|c|}{ Ancaman } \\
\hline 1 & $\begin{array}{l}\text { Persaingan dari perusahaan-perusahaan } \\
\text { lain yang menjalankan usaha yang sama, } \\
\text { terutama kompetitor-kompetitor yang } \\
\text { terdapat di sekitar lokasi kegiatan usaha } \\
\text { Perusahaan yang menawarkan harga } \\
\text { rumah yang lebih murah. }\end{array}$ & 0,085 & 3 & 0,255 \\
\hline 2 & \multirow{4}{*}{$\begin{array}{l}\text { Perubahan iklim sosila dan politik } \\
\text { merupakan salah satu faktor yang sangat } \\
\text { berpengaruh dalam keputusan investasi } \\
\text { aset seperti properti. } \\
\text { Masalah limbah rumah tangga yang tidak } \\
\text { ditangani dengan baik bisa menimbulkan } \\
\text { pencemaran terhadap lingkungan } \\
\text { perumahan sehingga dapat berpengaruh } \\
\text { terhadap tidak dikelola dengan baik dapat } \\
\text { menimbulkan pencemaran terhadap } \\
\text { produk perumahan. } \\
\text { Salah satu ancaman yang mungkin timbul } \\
\text { adalah terjadinya kebakaran dan bencana } \\
\text { alam yang dapat mengakibatkan kerugian } \\
\text { moril dan materil, baik } \\
\text { bagi pemilik bangunan maupun bagi } \\
\text { perusahaan. } \\
\text { Kegiatan usaha Perusahaan dipengaruhi } \\
\text { oleh perubahan nilai tukar Rupiah } \\
\text { terhadap Dollar dan } \\
\text { level susku bunga. Dampak dari suku } \\
\text { bunga yang terus naik bisa menimbulkan } \\
\text { penurunan penjualan, dikarenakan } \\
\text { berpengaruh terhadap kemampuan beli } \\
\text { calon pembeli. }\end{array}$} & 0,075 & 3 & 0,225 \\
\hline 3 & & 0,085 & 3 & 0,360 \\
\hline 4 & & 0,095 & 3 & 0,276 \\
\hline 5. & & 0,090 & 3 & 0,27 \\
\hline \multicolumn{2}{|c|}{ Jumlah } & & & 1,386 \\
\hline \multicolumn{2}{|r|}{ Total Nilai } & 1 & $\begin{array}{l}0,07 \\
0\end{array}$ & 3,291 \\
\hline
\end{tabular}

Dari hasil analisis IFE dan EFE didapatkan bahwa nilai hasil bertimbang IFE berjumlah 3,2325 sementara nilai hasil tertimbang EFE berjumlah 3,291. Dari analisis menujukan kondisi perusahaan terbilang berkembang dengan pesat sehingga mampu ditingkatkan kekuatanya untuk mencapai yang menguntungkan. Untuk itu dapat digunakan alternative strategi 1 yakni pengembangan (strategi agresif).

Tabel 5. Rata-rata tertimbang IFE dan EFE Matrikd Space. 


\begin{tabular}{|l|l|l|l|l|}
\hline & $\begin{array}{l}\text { Kuat } \\
3-4\end{array}$ & $\begin{array}{l}\text { Rata- } \\
\text { Rata 2 } \\
-2,99\end{array}$ & $\begin{array}{l}\text { Lemah } \\
1,99 \\
1,99\end{array}$ \\
\cline { 2 - 5 } & $\begin{array}{l}\text { Tinggi } \\
3-4\end{array}$ & I* $^{*}$ & II & III \\
\cline { 2 - 5 } $\begin{array}{l}\text { Menengah } \\
2-2,99\end{array}$ & IV & V & VI \\
\hline $\begin{array}{l}\text { Rendah } \\
1-1,99\end{array}$ & VII & VIII & IX \\
\hline
\end{tabular}

Keterangan : Royal tajur Residence memiliki nilai tertimbang IFE sebesar 3,2325 sementara nilai tertimbang EFE sebesar 3,291 .

\section{Koordinat SWOT}

Data matriks dari nilai hasil IFE dan nilai hasil EFE dapat diperoleh nomor koordinat SWOT untuk menentukan alternatif strategi perusahaan yang diambil. Untuk koordinat analisis internal dengan cara total skor kekuatan dikurangi total skor kelemahan dibagi 2. Sementara koordinat analisis eksternal dengan cara total skor peluang dikurangi total skor ancaman dibagi 2 . Berikut hasil perhitungan yang didapat:

a) Koordinat Analisis Internal = (Skor Total Kekuatan-Skor Total Kelemahan)

Koordinat Analisis Internal

$$
=\frac{(2,9225-0,31)}{2}
$$

Koordinat Analisis Internal $=2,7675$ b) Koordinat Analisis Eksternal = (Skor Total Peluang-Skor Total Kelemahan) Koordinat Analisis Eksternal

$$
=\frac{(1,905-1,386)}{2}
$$

Koordinat Analisis Eksternal $=1,212$

Jadi hasil dari nilai hasil IFE dan nilai hasil EFE didapat Titik Koordinat SWOT tertelak pada $(2,9225$ dan 1,212$)$ yang terletak pada kuadran I (Expansion) sehingga mendukung alternatif strategi agresif.

Tabel 6. Koordinat Matriks Space

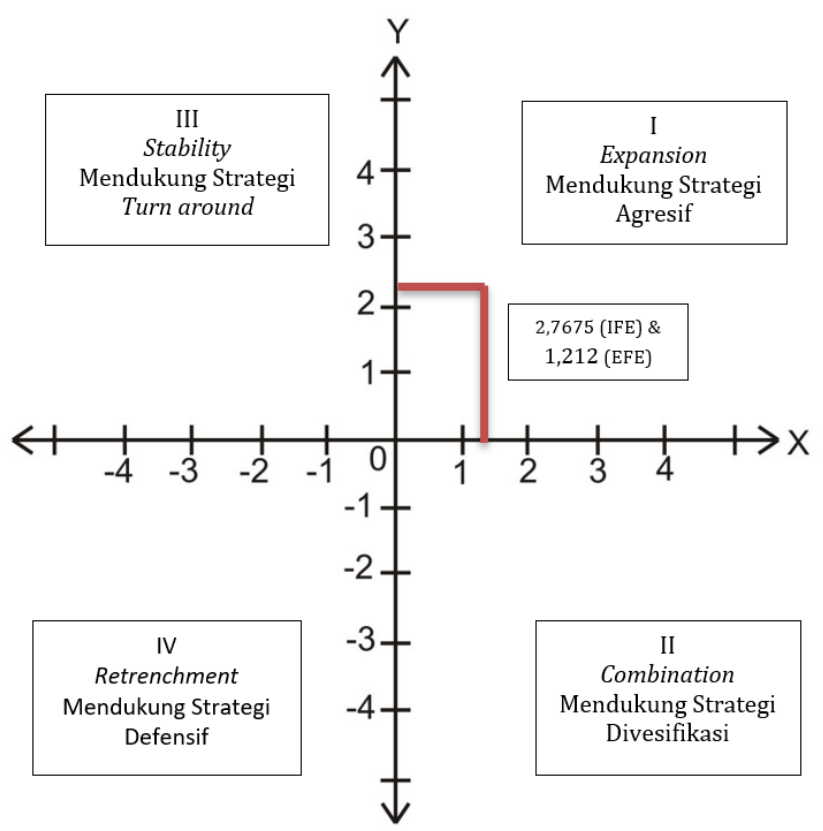


Tabel 7. Matriks SWOT

\begin{tabular}{|c|c|c|}
\hline FAKTOR INTERNAL & Kekuatan (Strenghtneses) & Kelemahan (Weakneses) \\
\hline FAKTOR EKSTERNAL & 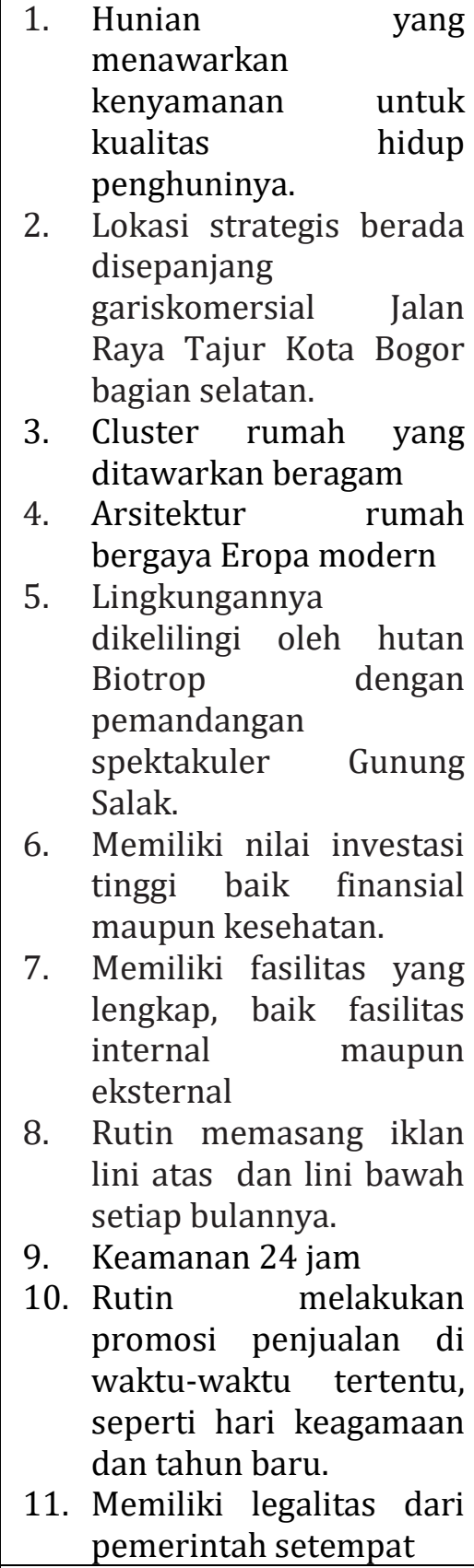 & $\begin{array}{l}\text { 1. Harganya relatif tinggi, } \\
\text { sehingga tidak semua } \\
\text { kalangan bisa membeli } \\
\text { rumah di Royal Tajur } \\
\text { Residence } \\
\text { pasar kelas menengah } \\
\text { keatas). } \\
\text { 2. Fasilitas umum dan } \\
\text { fasilitas sosial masih } \\
\text { dalam } \\
\text { pembangunan, sehingga } \\
\text { belum nisa digunakan oleh } \\
\text { penghuni Royal } \\
\text { Residence. }\end{array}$ \\
\hline Peluang (Opportunity) & $\begin{array}{l}\text { STRATEGI S-O } \\
\end{array}$ & STRATEGI W-O \\
\hline $\begin{array}{l}\text { 1. Makin mudahnya akses } \\
\text { menuju Bogor, dengan } \\
\text { akan dibangunnya jalan } \\
\text { raya Bogor Inner Ring Road } \\
\text { (BIRR) dan pembangunan } \\
\text { Tol Bocimi yang akan } \\
\text { segera beroperasi. } \\
\text { 2. Berhubungan baik dengan }\end{array}$ & $\begin{array}{l}\text { 1. Memaksimalkan } \\
\text { pembangunan dan } \\
\text { menjaga kualitas dari } \\
\text { berbagai aspek seperti } \\
\text { kualitas bangunan, kualitas } \\
\text { kenyaman dan kualitas } \\
\text { keamanan di setiap cluster } \\
\text { ssesuai dengan kebutuhan } \\
\text { masyarakat urban }\end{array}$ & $\begin{array}{l}\text { 1. Membuat hunian yang } \\
\text { harganya terjangkau } \\
\text { (S1,05). } \\
\text { 2. Mempercepat } \\
\text { pembangunan dan } \\
\text { menambah berbagai } \\
\text { fasilitas umum dan fasilitas } \\
\text { sosial dibutuhkan oleh }\end{array}$ \\
\hline
\end{tabular}




\begin{tabular}{|c|c|c|}
\hline $\begin{array}{l}\text { media massa (media } \\
\text { relation). } \\
\text { 3. Menjaga hubungan dengan } \\
\text { pelanggan/pembeli } \\
\text { (retention). } \\
\text { 4. Mendapatkan penghargaan } \\
\text { nasional sebagai The } \\
\text { Prospective Housing in } \\
\text { Bogor di acara } \\
\text { penghargaan properti } \\
\text { terbesar Indonesia } \\
\text { Property Award tahun } \\
\text { 2017. } \\
\text { 5. Pengembangan apartemen } \\
\text { Royal Height } \\
\text { 6. Kebutuhan masyarakat } \\
\text { urban mengenai hunian } \\
\text { yang alami }\end{array}$ & $\begin{array}{l}\text { (S1,06,S9,05,S5,01,S7,S3, } \\
\text { S11). } \\
\text { 2. Mempertahankan strategi } \\
\text { pemasaran yang sudah } \\
\text { dilakukan secara intensif di } \\
\text { berbagai lini media. } \\
\text { (S8,02,S10,03,08,01,05). } \\
\text { 3. Memanfaatkan } \\
\text { penghargaan } \\
\text { didapatkan dan arsitektur } \\
\text { bangunan yang khas } \\
\text { sebagai alat promosi (02, } \\
\text { S8, 04,S8,03). } \\
\text { 4. Terus berinovasi dalam } \\
\text { mengembangkan produk } \\
\text { sesuai dengan kebutuhan } \\
\text { masyarakat perkotaan (S2, } \\
\text { 01, S5. 05). } \\
\text { 5. Menjadikan para eksekutif } \\
\text { muda sebagai segemntasi } \\
\text { pasar yang potensial } \\
\text { (S2,04,S6,01). }\end{array}$ & $\begin{array}{l}\text { penghuni Royal Tajur } \\
\text { Residence untuk menunjang } \\
\text { setiap kegiatan manusia } \\
(\mathrm{S} 2,01) \text {. }\end{array}$ \\
\hline Ancaman (Trheats) & STRATEGI W-T & STRATEGI W-O \\
\hline 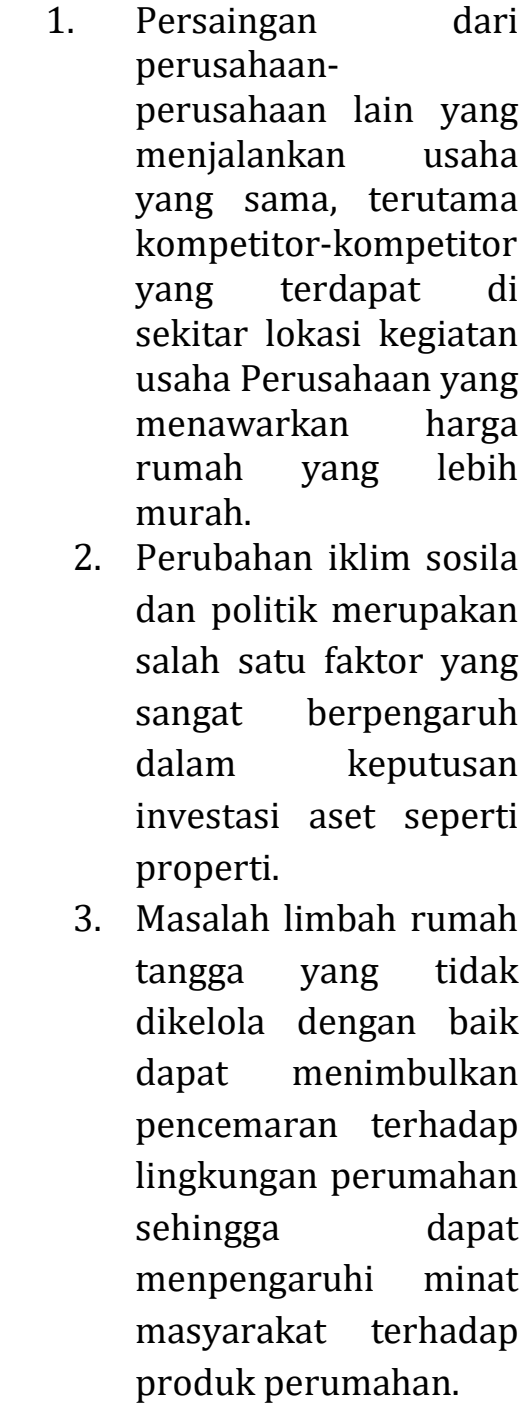 & 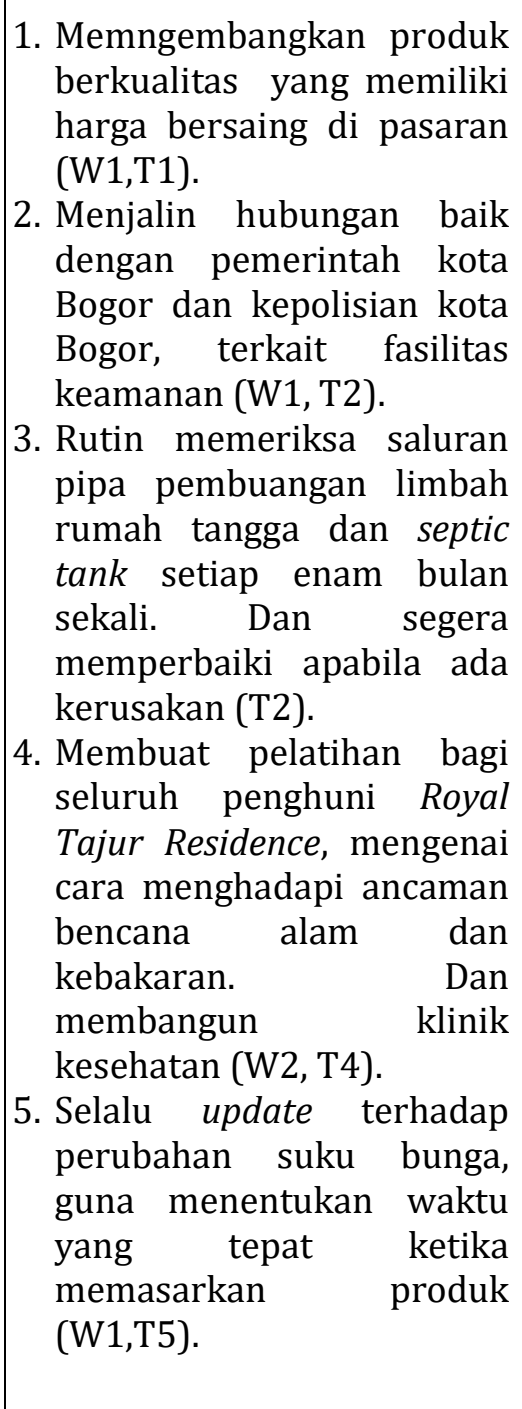 & $\begin{array}{l}\text { 1. Membuat berita secara } \\
\text { masiv mengenai } \\
\text { keuntungan untuk masa } \\
\text { depan yang diperoleh } \\
\text { ketika membeli rumah di } \\
\text { Royal Tajur Residence, } \\
\text { meski memiliki harga tinggi } \\
\text { (W1, 01,02,06). } \\
\text { 2. Aktif pada media sosial } \\
\text { dengan mempromosikan } \\
\text { unit perumahan yang } \\
\text { ditawarkan (W1, 02,03,04) }\end{array}$ \\
\hline
\end{tabular}


4. Salah satu ancaman yang mungkin timbul adalah terjadinya kebakaran dan bencana alam yang dapat mengakibatkan kerugian moril dan materil, baik bagi pemilik bangunan maupun bagi perusahaan.

5. Kegiatan usaha Perusahaan dipengaruhi oleh perubahan nilai tukar Rupiah terhadap Dollar dan level susku bunga. Dampak dari suku bunga yang terus naik bisa menimbulkan penurunan penjualan, dikarenakan berpengaruh terhadap kemampuan beli calon pembeli.

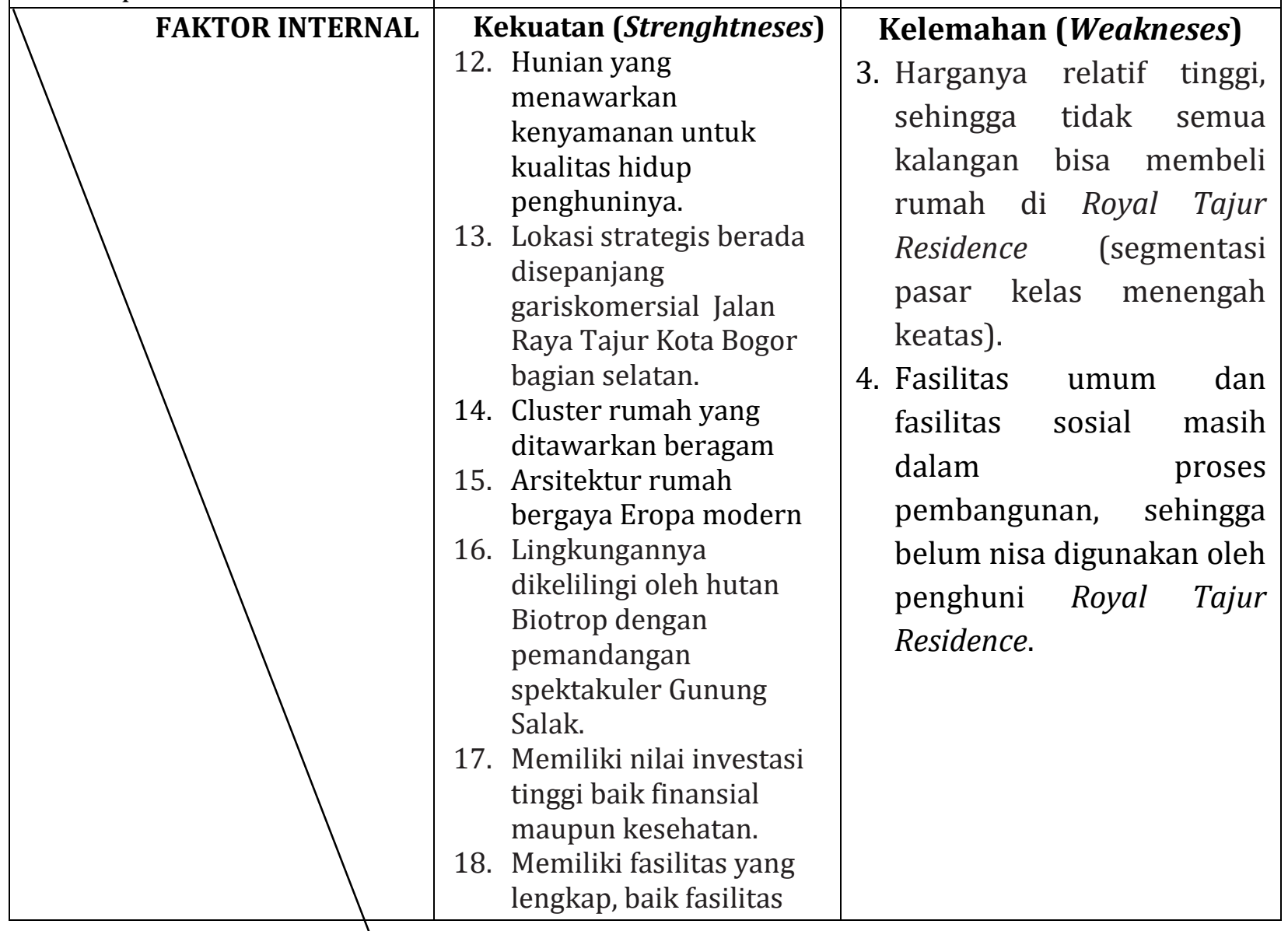




\begin{tabular}{|c|c|c|}
\hline FAKTOR EKSTERNAL & $\begin{array}{l}\text { internal maupun } \\
\text { eksternal } \\
\text { 19. Rutin memasang iklan } \\
\text { lini atas dan lini bawah } \\
\text { setiap bulannya. } \\
\text { 20. Keamanan } 24 \text { jam } \\
\text { 21. Rutin melakukan } \\
\text { promosi penjualan di } \\
\text { waktu-waktu tertentu, } \\
\text { seperti hari keagamaan } \\
\text { dan tahun baru. } \\
\text { 22. } \\
\text { Memiliki legalitas dari } \\
\text { pemerintah setempat }\end{array}$ & \\
\hline Peluang (Opportunity) & STRATEGI S-O & STRATEGI W-O \\
\hline $\begin{array}{l}\text { 7. Makin mudahnya akses } \\
\text { menuju Bogor, dengan } \\
\text { akan dibangunnya jalan } \\
\text { raya Bogor Inner Ring Road } \\
\text { (BIRR) dan pembangunan } \\
\text { Tol Bocimi yang akan } \\
\text { segera beroperasi. } \\
\text { 8. Berhubungan baik dengan } \\
\text { media massa (media } \\
\text { relation). } \\
\text { 9. Menjaga hubungan dengan } \\
\text { pelanggan/pembeli } \\
\text { (retention). } \\
\text { 10. Mendapatkan penghargaan } \\
\text { nasional sebagai The } \\
\text { Prospective Housing in } \\
\text { Bogor di acara } \\
\text { penghargaan properti } \\
\text { terbesar Indonesia } \\
\text { Property Award tahun } \\
\text { 2017. } \\
\text { 11.Pengembangan apartemen } \\
\text { Royal Height } \\
\text { Kebutuhan masyarakat } \\
\text { urban mengenai hunian } \\
\text { yang alami }\end{array}$ & $\begin{array}{l}\text { 6. Memaksimalkan } \\
\text { pembangunan dan } \\
\text { menjaga kualitas dari } \\
\text { berbagai aspek seperti } \\
\text { kualitas bangunan, kualitas } \\
\text { kenyaman dan kualitas } \\
\text { keamanan di setiap cluster } \\
\text { ssesuai dengan kebutuhan } \\
\text { masyarakat urban } \\
\text { (S1,06,S9,05,S5,01,S7,S3, } \\
\text { S11). } \\
\text { 7. Mempertahankan strategi } \\
\text { pemasaran yang sudah } \\
\text { dilakukan secara intensif di } \\
\text { berbagai lini media. } \\
\text { (S8,02,S10,03,08,01,05). } \\
\text { 8. Memanfaatkan } \\
\text { penghargaan yang } \\
\text { didapatkan dan arsitektur } \\
\text { bangunan yang khas } \\
\text { sebagai alat promosi (O2, } \\
\text { S8, O4,S8,03). } \\
\text { 9. Terus berinovasi dalam } \\
\text { mengembangkan produk } \\
\text { sesuai dengan kebutuhan } \\
\text { masyarakat perkotaan (S2, } \\
\text { O1, S5. O5). } \\
\text { Menjadikan para } \\
\text { 10. } \\
\text { eksekutif muda sebagai } \\
\text { segemntasi pasar yang } \\
\text { potensial (S2,04,S6,01). }\end{array}$ & $\begin{array}{l}\text { 3. Membuat hunian yang } \\
\text { harganya terjangkau } \\
\text { (S1,05). } \\
\text { 4. Mempercepat } \\
\text { pembangunan dan } \\
\text { menambah } \\
\text { fasilitas umum dan fasilitas } \\
\text { sosial dibutuhkan oleh } \\
\text { penghuni Royal Tajur } \\
\text { Residence untuk menunjang } \\
\text { setiap kegiatan manusia } \\
\text { (S2,01). }\end{array}$ \\
\hline Ancaman (Trheats) & STRATEGI W-T & STRATEGI W-O \\
\hline $\begin{array}{l}\text { 6ersaingan dari } \\
\text { perusahaan- } \\
\text { perusahaan lain yang } \\
\text { menjalankan usaha } \\
\text { yang sama, terutama } \\
\text { kompetitor-kompetitor } \\
\text { yang terdapat di } \\
\text { sekitar lokasi kegiatan } \\
\text { usaha Perusahaan yang }\end{array}$ & $\begin{array}{l}\text { 6. Memngembangkan produk } \\
\text { berkualitas yang memiliki } \\
\text { harga bersaing di pasaran } \\
\text { (W1,T1). } \\
\text { 7. Menjalin hubungan baik } \\
\text { dengan pemerintah kota } \\
\text { Bogor dan kepolisian kota } \\
\text { Bogor, terkait fasilitas }\end{array}$ & $\begin{array}{l}\text { 3. Membuat berita secara } \\
\text { masiv mengenai } \\
\text { keuntungan untuk masa } \\
\text { depan yang diperoleh } \\
\text { ketika membeli rumah di } \\
\text { Royal Tajur Residence, } \\
\text { meski memiliki harga tinggi }\end{array}$ \\
\hline
\end{tabular}




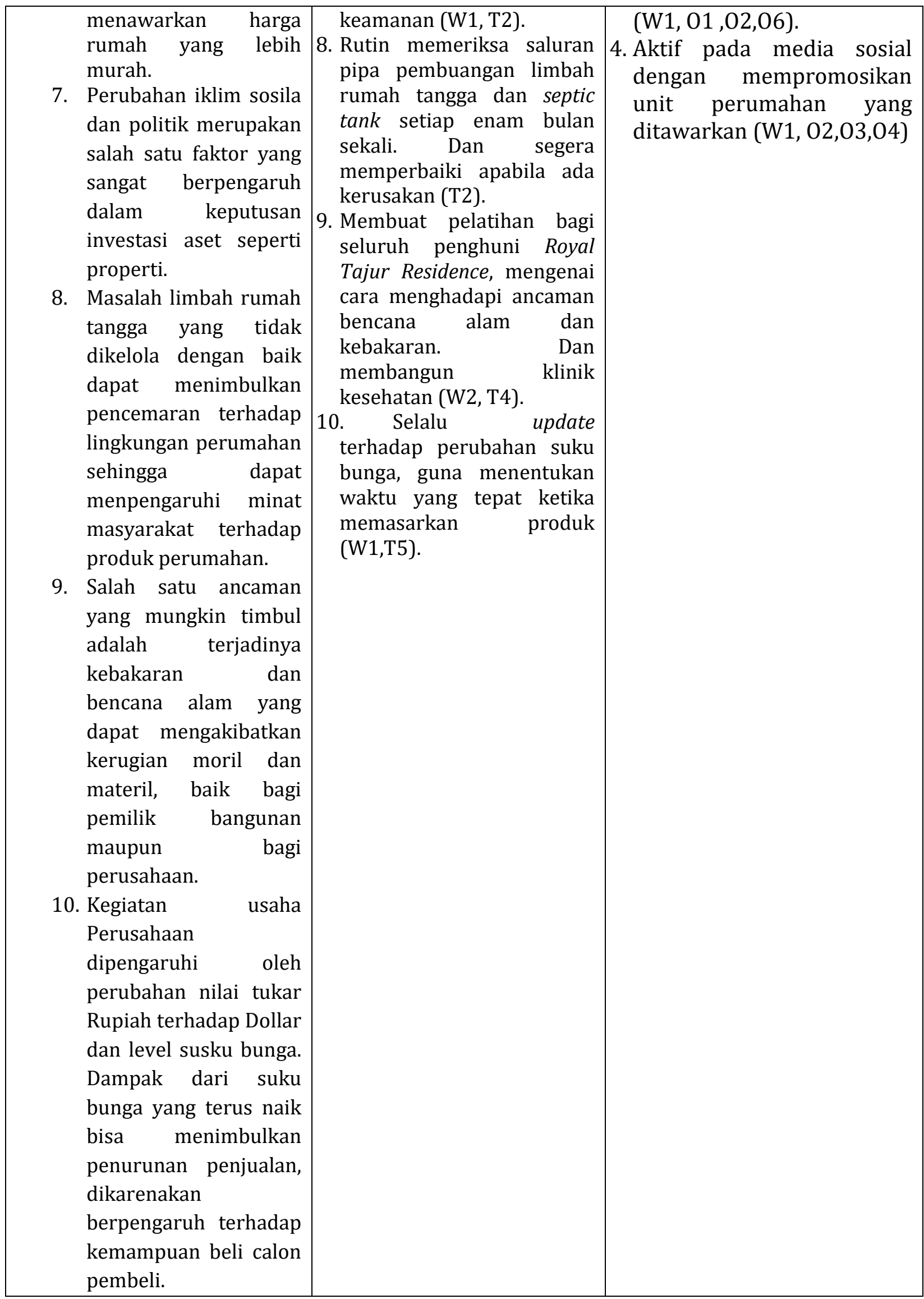




\section{KESIMPULAN DAN IMPLIKASI}

\section{Kesimpulan}

Proses strategi komunikasi pemasaran menggunakan strategi periklanan, promosi penjualan dan public relations dengan menggunakan media BTL (Below the Line) dan media ATL (Above the Line). Promosi merupakan faktor penarik minat calon pembeli, sehingga sangat penting dilakukan. Hasil dari analisis Matriks SWOT yang telah dilakukan bahwa konsisi perushaan dari perumahan Royal Tajur Residence berada di nomor urut satu yakni expansion dengan strategi agresif.

\section{Impelentasi}

Saran yang diajukan dalam penelitian ini adalah; mempertahankan strategi pemasaran dan meningkatkan intensitas promosi; berinovasi terhadap produk rumah yang ditawarkan sesuai dengan segmen pasar.

\section{DAFTAR PUSTAKA}

Alexander AH. 2017.Bima Arahkan Pengembangan Kota Bogor Ke Utara. Di unduh pada https://properti.kompas.com/re ad/2017/09/28/183535221/bimaarahkan-pengembangan-kota-bogorke-utara Diakses pada 05 April 2018.

Amalia N, Sukarelawati, Kusumadinata AA. Promosi Personal Selling Surat Kabar
Bogor Today Dalam Menarik Minat Pemasang Iklan. Jurnal Komunikatio. 3 (1): 9-20.

Hermawan A. 2012. Komunikasi Pemasaran. Jakarta (ID): Penerbit Erlangga.

Indrapraja RMI, Ratnamulyani IA, Fitriah M.

2015. Strategi Komunikasi Pemasaran Jungleland Adventure Theme Park Bogor Dalam Upaya Menarik Pengunjung. Jurnal Komunikatio. 1(1): 41-50.

Kotler A. 2004. Dasar-Dasar Pemasaran. Jakarta (ID): Penerbit Gramedia.

Kotler P, Keller K. 2009. Manajemen Pemasaran Edisi 13. Jakarta (ID): Penerbit Erlangga.

Muzakir I. 2017. Royal Tajur Raih The Prospective Housing in Bogor. Di unduh pada http://id.beritasatu.com/home/royaltajur-raih-the-prospective-housing-inbogor/166800 Diakses pada 25 April 2018.

Rakhmat J. 1998. Metode Penelitian Komunikasi. Bandung (ID): PT. Remaja Rosdakarya.

Rangkuti F. 2002. The Power of Brand : Teknik Mengelola Brand Equity dan Strategi Pengembangan Merek. Jakarta (ID): Gramedia.

Rangkuti F. 2014. Teknik Membedah Kasus Bisnis Analisis SWOT. Jakarta (ID): Gramedia.

Rasmi MN. 2009. Dampak Pembangunan Properti Terhadap Kesejahteraan Masyarakat Di Kota Bogor.[Skripsi]. Bogor (ID). Institut Pertanian Bogor. 